\title{
Development and experimental study on a pilot-scale feed pellet mill
}

\author{
Fei Peng ${ }^{1}$, Fang Fang ${ }^{2 *}$, Zhigang Huang ${ }^{1,3}$ \\ (1. School of Artificial Intelligence, Beijing Technology and Business University, Beijing 100048, China; \\ 2. College of Chemical Engineering, Zhengzhou University, Zhengzhou 450001, China; \\ 3. Beijing Key Laboratory of Quality Evaluation Technology for Hygiene and Safety of Plastics, \\ Beijing Technology and Business University, Beijing 100048, China)
}

\begin{abstract}
Pilot-scale pellet mill has many advantages and great potential application prospect. In this work, a structure of pilot-scale pellet mill was designed and the effects of moisture content $(12 \%-20 \%$ w.b. $)$, temperature $\left(55^{\circ} \mathrm{C}-95^{\circ} \mathrm{C}\right)$ and ring die speed (160-320 $\mathrm{r} / \mathrm{min}$ ) on the production and physical properties (pellet durability, bulk density and hardness) of the produced feed pellets were determined and analyzed. The results showed that pellet durability ranged from $90.47 \%$ to $96.92 \%$, bulk density $537.4 \mathrm{~kg} / \mathrm{m}^{3}$ to $62.2 \mathrm{~kg} / \mathrm{m}^{3}$, hardness $5.26 \mathrm{~kg}$ to $9.65 \mathrm{~kg}$ and production $26.51 \mathrm{~kg} / \mathrm{h}$ to $42.81 \mathrm{~kg} / \mathrm{h}$. Pellet durability was found to increase with the increase of temperature and moisture content, but to decrease with the increase of ring die speed. Bulk density showed a monotonic increase with temperature and ring die speed. Hardness increased with the increase of temperature, but exhibited a first ascending and then descending trends with the increase of moisture content. It also indicted that high ring die speed favored production. Due to its fast and cheap production in a suitable scale, the designed pilot scale pellet mill prototype and the comprehensive research would contribute to the production of feed pellets in various processing conditions with different feed formulas, like additive selection and so on, in order to meet diversified demands.
\end{abstract}

Keywords: feed, pilot-scale, pellet mill, experimental study, ring die speed

DOI: $10.25165 /$ j.ijabe.20201306.5826

Citation: Peng F, Fang F, Huang Z G. Development and experimental study on a pilot-scale feed pellet mill. Int J Agric \& Biol Eng, 2020; 13(6): 201-206.

\section{Introduction}

Feed costs account for up to $60 \%-70 \%$ of the total cost in aquaculture and livestock breeding industries ${ }^{[1-3]}$. Pellet feed, as the primary feed form, is by far the most widely used in the world. The higher bulk density, more consistent size facilitate the handling, transportation and storage. Compared with mashed or reground forms, pellet form can reduce the segregation of ingredients, resulting in less feed wastage and improved palatability ${ }^{[4-7]}$. More importantly, the higher gelatinization degree of the pellet feed attributes to higher strength and lower pulverization ratio, which will boost the nutrient uptake as well as the feed utilization ${ }^{[8,9]}$. However, pellets are inevitably subjected to friction, vibrate and pressure during the process of production and transportation, which is detrimental to the integrity of the pellet form.

Pellets quality refers to the ability to anti fragmentation and abrasion during handling without breaking up or generating a few fines. The technical quality can be expressed by the properties of bulk density, mechanical strength, durability (abrasion resistance of bulk pellets $)^{[10,11]}$. In feed industry, pelleting mainly involves to thermal and mechanical processing, aiming to agglomerate ingredients particles combined with temperature and moisture under pressure. Therefore, it is important to study the effects of processing parameters on the feed pelleting quality, so as to find the optimal conditions and finally achieve higher pellet quality and

Received date: 2020-04-06 Accepted date: 2020-07-28

Biographies: Fei Peng, PhD, Associate Professor, research interest: agricultural products processing technology and equipment. Email: feipeng@btbu.edu.cn; Zhigang Huang, $\mathrm{PhD}$, Professor, research interest: food processing machine, Email: huangzg@btbu.edu.cn.

*Corresponding author: Fang Fang, PhD, Associate Professor, research interest: agricultural science. College of Chemical Engineering, Zhengzhou University, No.100, Kexue Avenue, Zhengzhou 450001, Henan Province, China. Tel: +86-371-67739781, Email: fangf1001@163.com. lower consumption.

To understand and optimize the pelleting process, the compaction characteristics of various animal feedstuff have been measured in multiple studies ${ }^{[1,4,12,13]}$. Different raw materials were used to examine their pelleting properties. Moreover, many compression mathematical models, most of which are empirical or developed based on rheology, have been developed ${ }^{[14,15]}$. Among them, the single pellet press method has been widely used due to its fast and cheap operations in a small scale ${ }^{[1,16]}$

However, it is acknowledged that feed pelleting is complex which involves a series of unit operations in sequence of mixing, moisture conditioning, addition of additives, roller-die extrusion and subsequent cooling of the product ${ }^{[4,12,17]}$. The actual batch-scale process used to be studied using a single pellet test for its low cost and simplicity, but it often led to some inevitable deviations. On the other hand, tests of industrial scale can reflect the real production, but it is confronted with costly and difficult operations. Therefore, an alternative method is highly needed, which is the basis for this research. Thus, a proper scale pellet mill with adjustable parameters should be developed as the basis for feed pelleting research. However, no related studies have been reported.

Therefore, our research has two objectives: 1) to design and develop a pilot scale pellet mill used for feed production, and evaluate performance efficiency of the machine. 2) to investigate the effects of feedstuff moisture content $\left(55^{\circ} \mathrm{C}-95^{\circ} \mathrm{C}\right)$, temperature (12\%-20\% w.b.), and ring die speed (160-320 r/min) on pellet physical properties like pellet durability, bulk density and hardness as well as throughput capacity, so as to systematically evaluate performance efficiency of the machine.

\section{Materials and methods}

\subsection{Materials}

Based on the recommendation of National Research Council 
$(\mathrm{NRC})^{[18]}$ and the actual situation in China, the diet formulation for piglet was used in the study. The composition of the basal diet with nutrient levels was shown in Table 1.

Table 1 Composition of basal diet with nutrient levels

\begin{tabular}{lc}
\hline \multicolumn{1}{c}{ Item } & Content $/ \mathrm{g} \cdot \mathrm{kg}^{-1}$ \\
\hline Ingredients & \\
\hline Corn & 490 \\
Extruded corn & 100 \\
Extruded soybean meal & 180 \\
Wheat bran & 100 \\
DDGS (distiller dried grains with solubles) & 40 \\
Fish meal & 20 \\
Brewers dried yeast & 20 \\
Soybean oil & 10 \\
Premix & 40 \\
\hline Nutrient levels & \\
\hline Dry matter & 877 \\
Crude protein & 182.66 \\
Calcium & 9.01 \\
N-Py-P & 3.95 \\
Crude ash & 30.98 \\
Crude fiber & 29.31 \\
Na & 1.67 \\
\hline
\end{tabular}

\subsection{Methods}

As shown in Figures 1 and 2, a pilot scale feed pellet mill with the production maximum capacity of $50 \mathrm{~kg} / \mathrm{h}$ was designed and developed. This was mainly composed of a feeder, a conditioner, a pelleting chamber and other parts, as well as drive system and control system.

Structure parameters of the pilot scale feed pellet mill were shown in Table 2. In working, feed ingredients were poured into hopper and then delivered into conditioner chamber by helical blade. And then feed ingredients were conditioned mixed with saturated vapor, followed by hydrothermal reaction happened. Thus, temperature and moisture content values of feed ingredients changed. In this study, feed ingredients can achieve desired temperature and moisture content values by adjusting speed of conditioner spindle and flow rate of saturated vapor. Then, the conditioned feed ingredients were transported into the pelleting chamber, with a ring die driven by variable-speed motor. Under the extruding force caused by the ring die and roller, feed pellets were extruded out of die holes which processed in the ring die. Next, pellet feeds were dried by flowing air to remove excessive moisture and reduce the temperature, followed by immediately analyzed for physical properties based on standard procedures.

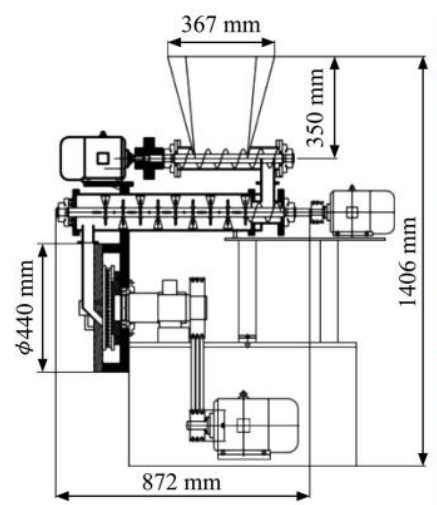

a. Structure diagram of design

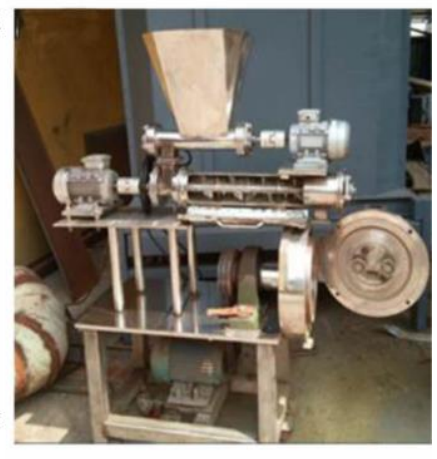

b. Prototype
Figure 1 Design and prototype of pilot-scale ring die pellet mill

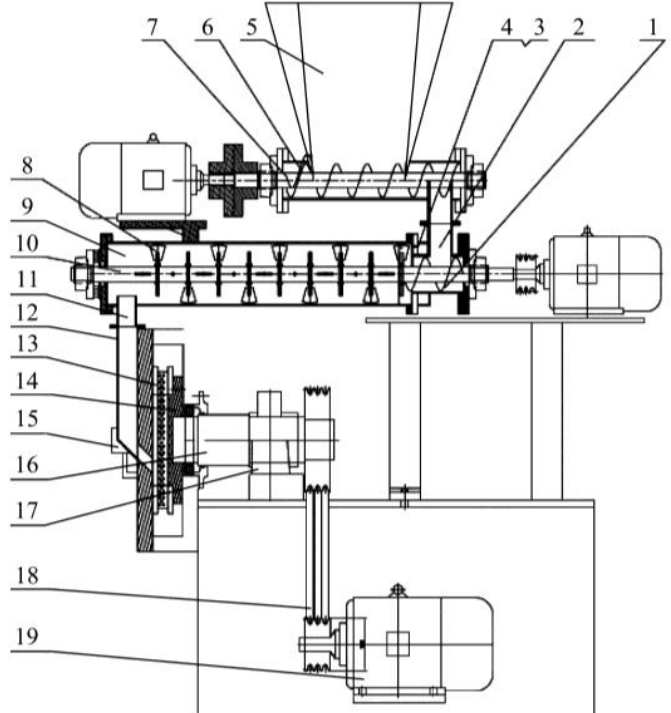

1. Screw vane 2. Inlet of conditioner 3. Steam chamber 4. Steam passage 5. Hopper 6. Helical blade 7. Feeder spindle 8. Blade 9. Conditioner chamber 10. Conditioner spindle 11. Outlet of conditioner 12. Control door 13. Ring die 14. Installation disk 15. Installation sleeve for roller 16. Mill spindle 17. Bearing 18. Drive belt 19. Variable-speed motor

Figure 2 Structure composition of pilot scale feed pellet mill

Table 2 Structural parameters of pilot scale feed pellet mill

\begin{tabular}{clcc}
\hline Category & \multicolumn{1}{c}{ Item } & Parameter & Unit \\
\hline \multirow{2}{*}{ Feeder } & Feeder shaft diameter & 35 & $\mathrm{~mm}$ \\
& Feeder pitch & 57 & $\mathrm{~mm}$ \\
\hline \multirow{2}{*}{ Conditioner } & Number of steam inlets & 10 & - \\
& Blade installation angle & 38.1 & $\left({ }^{\circ}\right)$ \\
\hline \multirow{3}{*}{ Pelleting chamber } & Inner diameter of ring die & 180 & $\mathrm{~mm}$ \\
& Width of ring die & 15 & $\mathrm{~mm}$ \\
& Number of rollers & 2 & - \\
& Diameter of roller & 70 & $\mathrm{~mm}$ \\
& Eccentric distance of roller & 5 & $\mathrm{~mm}$ \\
\hline Whole prototype & Power & 18 & $\mathrm{~kW}$ \\
\hline
\end{tabular}

\subsection{Performance evaluation}

\subsubsection{Pellet durability}

According to ASAE Standard S269.4 $4^{[19]}$, pellet durability was determined using a durability tester. The durability tester consisted of two tumbling boxes with the width of $130 \mathrm{~mm}$. Feed samples weighing $100 \mathrm{~g}$ were poured into the device and tumbled for $10 \mathrm{~min}$ at $50 \mathrm{r} / \mathrm{min}$. Then, the samples were sieved with screen to remove the fines and broken pellets, followed by weighing the pellets that were retained on the sieve. The PDI was calculated as the percentage of the pellets retained on the sieve after test of the whole pellets before test.

\subsubsection{Moisture content}

According to ASAE Standard S358.2 $2^{[20]}$ and indicated in ASAE Standard S269.4 $4^{[19,21]}$, moisture content of feed pellets was measured by using oven-drying for $72 \mathrm{~h}$ at $60^{\circ} \mathrm{C}$.

\subsubsection{Pellet hardness}

Pellet hardness was determined using a Kahl device (AMANDUS KAHL GmbH and Co., KG, Reinbek, Germany). Single pellet sample with the same size were put between two plates, followed by gradually increasing pressure until sample was broken ${ }^{[21,22]}$. The force that was needed to break the pellets means pellet hardness.

\subsubsection{Determination of throughput capacity}

The capacity of the motorized rice grader was calculated as that production divided by the corresponding time. 


\subsection{Experimental design}

To evaluate the performance of the machine, experiments were conducted based on the software regression analysis 8.0.6 Design-Expert and response surface analysis method. The processing parameters (moisture content $X_{1}$, temperature $X_{2}$, and ring die speed $X_{3}$ ) shown in Table 3, were selected as the independent variables. Accordingly, the quality attributes (pellet durability index, bulk density, and pellet hardness) and throughput capacity were selected as evaluating indicators, thus the performance evaluation experiments were carried out under the quadratic orthogonal rotation design.

Table 3 Independent numerical and categorical variables and their levels

\begin{tabular}{lcccccc}
\hline & & \multicolumn{5}{c}{ Code variable levels } \\
\cline { 3 - 7 } Numerical variable & Symbol & -2 & -1 & 0 & 1 & 2 \\
\hline Moisture content $/ \%$ & $X_{1}$ & 12 & 14 & 16 & 18 & 20 \\
Temperature $/{ }^{\circ} \mathrm{C}$ & $X_{2}$ & 55 & 65 & 75 & 85 & 95 \\
Ring die speed $/ \mathrm{r} \cdot \mathrm{min}^{-1}$ & $X_{3}$ & 160 & 200 & 240 & 280 & 320 \\
\hline
\end{tabular}

Note: Moisture content and temperature refers to the state of feedstuff after conditioning but before pelleting.

As shown in Table 4, twenty-three experiments were conducted with five replications to obtain reliable estimation of experimental results. A second-order polynomial equation applied to express the effects of the independent variables on the evaluating indicators in terms of linear, quadratic and the interactions was calculated as:

$$
y=b_{0}+\sum_{i=1}^{n} b_{i} x_{i}+\sum_{i=1}^{n} b_{i i} x_{i}^{2}+\sum_{i=1}^{n} \sum_{j=1}^{n} b_{i j} x_{i} x_{j}+\mathcal{E}
$$

\section{Results and discussion}

\subsection{Composition of diet formulation}

Diet formulation used for pelleting was listed in Table 1 . Gross composition of the formulation contained $877 \mathrm{~g}$ of dry

matter, $182.66 \mathrm{~g}$ of crude protein, $9.01 \mathrm{~g}$ of calcium, $3.95 \mathrm{~g}$ of N-Py-P, $30.98 \mathrm{~g}$ of crude ash and $29.31 \mathrm{~g}$ of crude fiber in per kilogram of diet. This composition satisfied well with requirements for piglet. Initial moisture content of the raw material was $10.62 \%$ (w.b.) and density of that was $482.68 \mathrm{~kg} / \mathrm{m}^{3}$. The measured experimental data from different process conditions were presented in Table 5.

Table 4 Experimental design layout

\begin{tabular}{|c|c|c|c|c|c|c|}
\hline \multirow{2}{*}{ Run } & \multicolumn{3}{|c|}{ Coded variables } & \multicolumn{3}{|c|}{ Actual variables } \\
\hline & $x_{1}$ & $x_{2}$ & $x_{3}$ & $X_{1} / \mathrm{s}$ & $X_{2} /{ }^{\circ} \mathrm{C}$ & $X_{3} / \mathrm{r} \cdot \min ^{-1}$ \\
\hline 1 & 1 & 1 & 1 & 18 & 85 & 280 \\
\hline 2 & 1 & 1 & -1 & 18 & 85 & 200 \\
\hline 3 & 1 & -1 & 1 & 18 & 65 & 280 \\
\hline 4 & 1 & -1 & -1 & 18 & 65 & 200 \\
\hline 5 & -1 & 1 & 1 & 14 & 85 & 280 \\
\hline 6 & -1 & 1 & -1 & 14 & 85 & 200 \\
\hline 7 & -1 & -1 & 1 & 14 & 65 & 280 \\
\hline 8 & -1 & -1 & -1 & 14 & 65 & 200 \\
\hline 9 & 2 & 0 & 0 & 20 & 75 & 240 \\
\hline 10 & -2 & 0 & 0 & 12 & 75 & 240 \\
\hline 11 & 0 & 2 & 0 & 16 & 95 & 240 \\
\hline 12 & 0 & -2 & 0 & 16 & 55 & 240 \\
\hline 13 & 0 & 0 & 2 & 16 & 75 & 320 \\
\hline 14 & 0 & 0 & -2 & 16 & 75 & 160 \\
\hline 15 & 0 & 0 & 0 & 16 & 75 & 240 \\
\hline 16 & 0 & 0 & 0 & 16 & 75 & 240 \\
\hline 17 & 0 & 0 & 0 & 16 & 75 & 240 \\
\hline 18 & 0 & 0 & 0 & 16 & 75 & 240 \\
\hline 19 & 0 & 0 & 0 & 16 & 75 & 240 \\
\hline 20 & 0 & 0 & 0 & 16 & 75 & 240 \\
\hline 21 & 0 & 0 & 0 & 16 & 75 & 240 \\
\hline 22 & 0 & 0 & 0 & 16 & 75 & 240 \\
\hline 23 & 0 & 0 & 0 & 16 & 75 & 240 \\
\hline
\end{tabular}

Table 5 Experimental data measured under treatment combinations of various runs

\begin{tabular}{|c|c|c|c|c|c|c|c|c|}
\hline Treatment & $\mathrm{PDI} / \%$ & $\mathrm{SD}$ & Bulk Density $/ \mathrm{kg} \cdot \mathrm{m}^{-3}$ & $\mathrm{SD}$ & Hardness/kg & $\mathrm{SD}$ & Throughput capacity $/ \mathrm{kg} \cdot \mathrm{h}^{-1}$ & SD \\
\hline 1 & 95.71 & 0.44 & 582.9 & 7.2 & 9.65 & 0.21 & 41.84 & 2.16 \\
\hline 2 & 97.82 & 0.36 & 564.4 & 9.1 & 9.11 & 0.17 & 33.27 & 1.63 \\
\hline 3 & 92.65 & 1.17 & 593.0 & 5.2 & 6.85 & 0.08 & 39.52 & 1.40 \\
\hline 4 & 93.08 & 0.69 & 551.7 & 10.4 & 6.55 & 0.11 & 30.81 & 0.92 \\
\hline 5 & 93.11 & 0.70 & 586.9 & 8.2 & 8.10 & 0.16 & 40.47 & 0.84 \\
\hline 6 & 96.25 & 0.45 & 573.5 & 8.9 & 8.42 & 0.18 & 33.55 & 1.55 \\
\hline 7 & 90.47 & 0.83 & 561.6 & 5.6 & 6.26 & 0.05 & 38.20 & 1.74 \\
\hline 8 & 91.94 & 1.21 & 537.4 & 9.1 & 6.82 & 0.18 & 32.42 & 0.75 \\
\hline 9 & 95.87 & 0.64 & 560.1 & 13.1 & 6.73 & 0.15 & 39.25 & 0.38 \\
\hline 10 & 91.24 & 0.45 & 558.4 & 5.2 & 6.15 & 0.14 & 37.55 & 2.41 \\
\hline 11 & 94.93 & 0.28 & 590.7 & 8.1 & 9.62 & 0.23 & 37.02 & 2.72 \\
\hline 12 & 92.38 & 0.11 & 553.1 & 7.5 & 5.34 & 0.15 & 35.23 & 1.90 \\
\hline 13 & 93.43 & 0.43 & 612.2 & 9.0 & 7.95 & 0.21 & 42.76 & 2.61 \\
\hline 15 & 96.11 & 0.32 & 583.6 & 8.6 & 8.29 & 0.14 & 38.22 & 0.41 \\
\hline 16 & 95.48 & 0.66 & 582.1 & 8.9 & 8.46 & 0.11 & 37.50 & 0.76 \\
\hline 17 & 95.62 & 0.45 & 567.2 & 10.5 & 7.71 & 0.12 & 39.83 & 0.90 \\
\hline 18 & 96.41 & 0.25 & 588.5 & 5.1 & 8.13 & 0.08 & 36.47 & 0.65 \\
\hline 19 & 94.87 & 0.37 & 574.7 & 12.2 & 8.05 & 0.05 & 41.97 & 1.52 \\
\hline 20 & 94.42 & 1.15 & 571.8 & 10.7 & 7.91 & 0.16 & 42.81 & 1.18 \\
\hline 21 & 95.33 & 0.42 & 580.5 & 6.5 & 8.07 & 0.10 & 39.52 & 2.05 \\
\hline 22 & 95.45 & 0.71 & 568.3 & 9.2 & 7.78 & 0.19 & 38.11 & 0.93 \\
\hline 23 & 96.37 & 0.40 & 579.5 & 9.7 & 8.02 & 0.12 & 38.76 & 1.75 \\
\hline
\end{tabular}

Notes: PDI means pellet durability index, SD means standard deviation. 


\subsection{Pellet durability index}

Pellet durability index was measured to reflect the mechanical strength of pellet feed to withstand shear and impact resistances. Higher value of pellet durability means the pellet feed is more stable during the processes of storage, transportation, handling and feeding ${ }^{[9,23]}$. The response surface plotted in Figure 3 manifested that feed pellet durability decreased with ring die speed in the range of 160-320 r/min, but increased with temperature, moisture content and in the range of $55^{\circ} \mathrm{C}-95^{\circ} \mathrm{C}$ and $12 \%-20 \%$ w.b., respectively. These results are in accordance with other researches ${ }^{[24]}$, where increased moisture content and temperature of feed blends during extrusion process, increased durability values of aquafeed. This was attributed to the fact that the feedstuff with higher temperature and moisture content can cohere stronger due to higher starch gelatinization. In addition, higher ring die speed will be helpful in pelleting due to the longer time and bigger force. The values of feed pellet durability under experimental conditions were given in Table 5. It is believed that the extent of heat and moisture treatment, along with the level of starch transformation as well as extrusion speed between the ring die and roller influence feed pellet durability index.

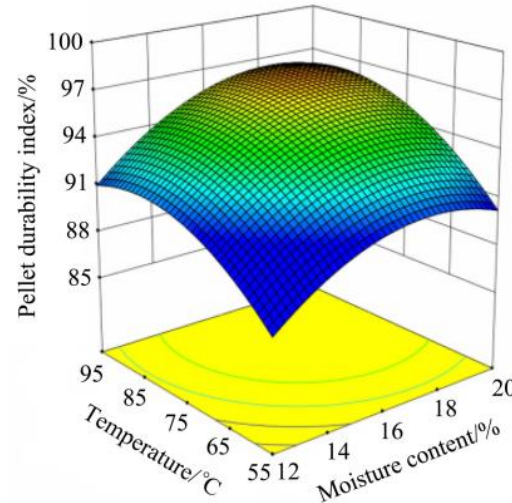

a. Moisture content and temperature at $240 \mathrm{r} / \mathrm{min}$

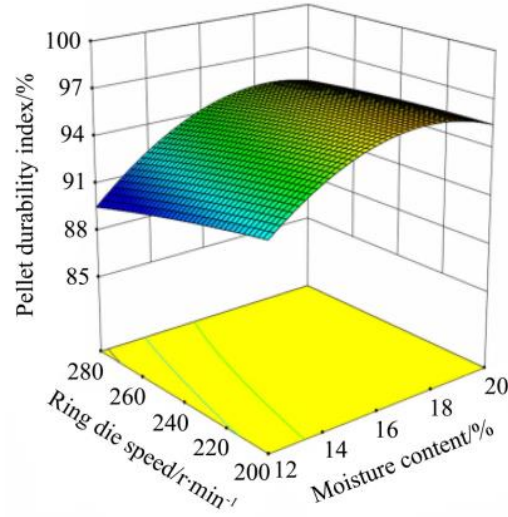

b. Moisture content and ring die speed at $75^{\circ} \mathrm{C}$

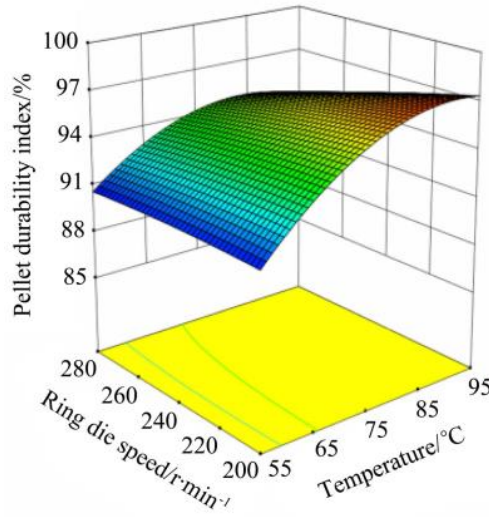

c. Temperature and ring die speed at $16 \%$ moisture content

Figure 3 Response surface plots of feed pellet durability index for effects of moisture content, temperature and ring die speed on pellet durability index

\subsection{Bulk density}

Bulk density of pellet feed was plotted as functions of temperature and ring die speed in Figure 4. Statistical results showed that increased temperature of feedstuff and ring die speed significantly affected the increase of bulk density. Similar bulk density was reported ${ }^{[25,26]}$, where higher die speed increased density values of wood pellets and corn stover pellets, respectively. As shown in Table 6, ANOVA indicated moisture content had no significant effect on bulk density and hence response surface models and plots of interaction effect involving moisture content were not shown. The experimental values of bulk density of pellet feed under different designed pelleting conditions were presented in Table 5.

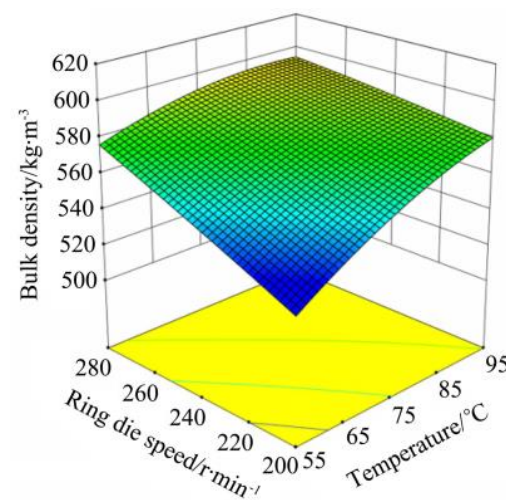

Figure 4 Response surface plots of feed bulk density for the effect of temperature and ring die speed at $16 \%$ moisture content

Table 6 Analysis of variance (ANOVA) for pellet durability index and bulk density

\begin{tabular}{|c|c|c|c|c|c|c|c|c|c|}
\hline \multirow[b]{2}{*}{ Source } & \multicolumn{5}{|c|}{ Pellet durability index } & \multicolumn{4}{|c|}{ Bulk density } \\
\hline & df & $\mathrm{SS}$ & MS & $F$-value & $p$-value & SS & MS & $F$-value & $p$-value \\
\hline Model & 9 & 72.16 & 8.02 & 9.32 & 0.0002 & 6392.21 & 710.25 & 13.43 & $<0.0001$ \\
\hline$X_{1}$ & 1 & 17.54 & 17.54 & 20.38 & 0.0006 & 81.00 & 81.00 & 1.53 & 0.2378 \\
\hline$X_{2}$ & 1 & 24.63 & 24.63 & 28.62 & 0.0001 & 1211.04 & 1211.04 & 22.90 & 0.0004 \\
\hline$X_{3}$ & 1 & 12.48 & 12.48 & 14.50 & 0.0022 & 3806.89 & 3806.89 & 71.97 & $<0.0001$ \\
\hline$X_{1} X_{2}$ & 1 & 0.090 & 0.090 & 0.10 & 0.7511 & 432.18 & 432.18 & 8.17 & 0.0134 \\
\hline$X_{1} X_{3}$ & 1 & 0.54 & 0.54 & 0.62 & 0.4443 & 61.61 & 61.61 & 1.16 & 0.3001 \\
\hline$X_{2} X_{3}$ & 1 & 1.40 & 1.40 & 1.63 & 0.2240 & 141.12 & 141.12 & 2.67 & 0.1264 \\
\hline$X_{1}^{2}$ & 1 & 9.05 & 9.05 & 10.51 & 0.0064 & 629.52 & 629.52 & 11.90 & 0.0043 \\
\hline$X_{2}^{2}$ & 1 & 8.27 & 8.27 & 9.60 & 0.0085 & 69.28 & 69.28 & 1.31 & 0.2730 \\
\hline$X_{3}^{2}$ & 1 & 0.74 & 0.74 & 0.86 & 0.3706 & 19.48 & 19.48 & 0.37 & 0.5544 \\
\hline Lack of Fit & 5 & 7.66 & 1.53 & 3.47 & 0.0580 & 264.36 & 52.87 & 1.00 & 0.4751 \\
\hline Pure Error & 8 & 3.53 & 0.44 & - & - & 423.24 & 52.91 & - & - \\
\hline
\end{tabular}




\subsection{Hardness}

The regression model and its statistical information were provided in Figure 5, which indicated that hardness of pellet feed increased with temperature and ranged from 6.28 to $9.65 \mathrm{~kg}$. In addition, Hardness of pellet feed exhibited ascending-descending trends with the increasing moisture content in the range of $12 \%$ $20 \%$ of pellet feed. This may be because appropriate moisture content within a certain range contributes to better adhesion among micro particles, thus benefit on resisting fragmentation. Ring die speed had no significant effect on hardness (Table 7). Hardness is in positive relationship with temperature, and hardness increased with temperature. Similar results were observed from other researches ${ }^{[8,23,27]}$. The treatment combination effects of moisture content and temperature on hardness of pellet feed were presented in Table 5 .

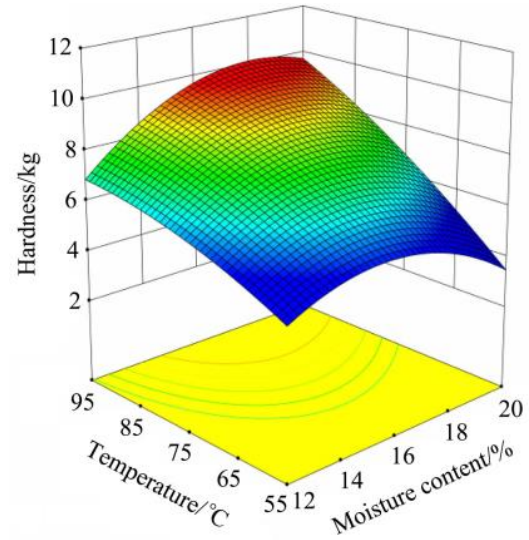

Figure 5 Response surface plots of feed hardness for the effect of temperature and moisture content at $240 \mathrm{r} / \mathrm{min}$

Table 7 Analysis of variance (ANOVA) for hardness and throughput capacity

\begin{tabular}{|c|c|c|c|c|c|c|c|c|c|}
\hline \multirow[b]{2}{*}{ Source } & \multicolumn{5}{|c|}{ Hardness } & \multicolumn{4}{|c|}{ Throughput capacity } \\
\hline & df & SS & MS & $F$-value & $p$-value & SS & MS & $F$-value & $p$-value \\
\hline Model & 9 & 24.60 & 2.73 & 37.56 & $<0.001$ & 314.17 & 34.91 & 11.58 & $<0.0001$ \\
\hline$X_{1}$ & 1 & 0.86 & 0.86 & 11.89 & 0.0043 & 1.10 & 1.10 & 0.37 & 0.5558 \\
\hline$X_{2}$ & 1 & 18.84 & 18.84 & 258.88 & $<0.0001$ & 8.41 & 8.41 & 2.79 & 0.1188 \\
\hline$X_{3}$ & 1 & 0.02 & 0.02 & 0.31 & 0.5876 & 243.36 & 243.36 & 80.73 & $<0.0001$ \\
\hline$X_{1} X_{2}$ & 1 & 0.46 & 0.46 & 6.33 & 0.0258 & 0.25 & 0.25 & 0.081 & 0.7801 \\
\hline$X_{1} X_{3}$ & 1 & 0.37 & 0.37 & 5.08 & 0.0421 & 2.64 & 2.64 & 0.88 & 0.3660 \\
\hline$X_{2} X_{3}$ & 1 & 0.03 & 0.03 & 0.40 & 0.5401 & 0.13 & 0.13 & 0.041 & 0.8418 \\
\hline$X_{1}^{2}$ & 1 & 3.88 & 3.88 & 53.30 & $<0.0001$ & 2.63 & 2.63 & 0.87 & 0.3675 \\
\hline$X_{2}^{2}$ & 1 & 0.35 & 0.35 & 4.80 & 0.0474 & 21.19 & 21.19 & 7.03 & 0.0200 \\
\hline$X_{3}^{2}$ & 1 & 0.03 & 0.03 & 0.44 & 0.5166 & 43.45 & 43.45 & 14.41 & 0.0022 \\
\hline Lack of Fit & 5 & 0.50 & 0.10 & 1.83 & 0.2135 & 5.30 & 1.06 & 0.25 & 0.9282 \\
\hline Pure Error & 8 & 0.44 & 0.06 & - & - & 33.89 & 4.24 & - & - \\
\hline
\end{tabular}

\subsection{Production}

The mean comparison of pelleting capacity in response to various factors shown in Table 6 indicated increased ring die speed had a corresponding increased throughput capacity. This may be because increased the ring die speed improved the ability of the machine to squeeze the material out of the pelleting chamber, hence more feedstuff can be extruded by the ring die and roller. Thus, more feed was produced and throughput capacity of feed pellet increased in per hour. ANOVA (Table 7) showed that moisture content and temperature had no significant effect on throughput capacity and hence response surface models and plots of interaction effect associated with moisture content and temperature effect were not shown. The regression model and its statistical information are given in Table 8.

Table 8 Final equations in terms of coded factors after excluding the insignificant terms for pellet durability index, bulk density, hardness and throughput capacity

\begin{tabular}{|c|c|c|c|c|}
\hline Coded model equation & $R^{2}$ & $\begin{array}{l}\operatorname{Adj} \\
R^{2}\end{array}$ & $\begin{array}{c}\text { Pred } \\
R^{2}\end{array}$ & $\begin{array}{l}\text { Adeq } \\
\text { precision }\end{array}$ \\
\hline$Y_{P D I}=95.49+1.05 M+1.24 T-0.57 M^{2}-0.54 T^{2}$ & 0.87 & 0.77 & 0.19 & 11.14 \\
\hline $\begin{aligned} Y_{B D}= & 577.12+8.70 T+15.43 S-7.35 M \cdot T- \\
& 4.73 M^{2}\end{aligned}$ & 0.90 & 0.84 & 0.62 & 14.56 \\
\hline $\begin{aligned} Y_{H D}= & 8.08+0.23 M+1.09 T+0.24 M \cdot T+ \\
& 0.22 M \cdot S-0.37 M^{2}-0.11 T^{2}\end{aligned}$ & 0.96 & 0.94 & 0.82 & 24.40 \\
\hline$Y_{T C}=39.11+3.90 S-0.87 T^{2}-1.24 S^{2}$ & 0.89 & 0.81 & 0.75 & 14.08 \\
\hline
\end{tabular}

Notes: $M$ is moisture content; $T$ is temperature; $S$ is ring die speed.

\section{Conclusions}

In the present study, a pilot scale pellet mill prototype was designed and developed for feed pelleting. To systematically evaluate performance experiments of the machine and further study on the pelletizing process, the effects of moisture content $\left(55^{\circ} \mathrm{C}-95^{\circ} \mathrm{C}\right)$, temperature $(12 \%-20 \%$ w.b. $)$, and ring die speed (160-320 r/min) on physical properties of feed pellets produced by the machine, as well as throughput capacity, were determined and analyzed. The following conclusions regarding their impact on pellet quality attributes were drawn:

The average pellet durability, bulk density and hardness of feed pellets, and throughput capacity of the machine ranged from $90.47 \%$ to $96.92 \%, 537.4$ to $62.2 \mathrm{~kg} / \mathrm{m}^{3}, 5.26$ to $9.65 \mathrm{~kg}$ and 26.51 to $42.81 \mathrm{~kg} / \mathrm{h}$, respectively. Pellet durability index was found to increase with the increase of temperature and moisture content, but decrease with the increase of ring die speed. Moisture content had no effects on bulk density, whereas increasing temperature and ring die speed increased bulk density. Hardness increased with temperature, and exhibited ascending-descending trends with the increasing moisture content. Increased ring die speed resulted in increasing in throughput capacity.

The comprehensive research, especially pilot scale pellet mill prototype designed and developed in the study, will contribute to the production of feed pellets under various formulas and processing conditions. Furthermore, the pilot scale pellet mill can also be used to improve feed formula, study feed additive and meet 
diversified demands due to its fast and cheap production in a very suitable scale.

\section{Acknowledgement}

The authors acknowledge that this work was financially supported by National Natural Science Foundation of China (Grant No. 52005012).

\section{[References]}

[1] Jiang Q H, Wu K, Sun Y. Modeling and analysis of pelletization process based on a multi-hole pelletizing device. Int J Agric \& Biol Eng, 2019; 12(1): 17-23.

[2] Ghasemi A, Chayjan R A, Najafabadi H J. Optimization of granular waste production based on mechanical properties. Waste Management, 2018; 75: 82-93.

[3] Abdollahi M R, Ravindran V, Svihus B. Pelleting of broiler diets: An overview with emphasis on pellet quality and nutritional value. Animal Feed Science and Technology, 2013; 179(1-4): 1-23.

[4] Svihus B, Zimonja O. Chemical alterations with nutritional consequences due to pelleting animal feeds: a review. Animal Production Science, 2011, 51(7): 590-596.

[5] Lv M B, Yan L, Wang Z G, An S, Wu M M, Lv Z Z. Effects of feed form and feed particle size on growth performance, carcass characteristics and digestive tract development of broilers. Animal Nutrition, 2015; 1(3): 252-256

[6] Behnke K C. Feed manufacturing technology: current issues and challenges. Animal Feed Science and Technology, 1996; 62(1): 49-57.

[7] Boac J A, Casada M E, Maghirang R G. Feed pellet and corn durability and breakage during repeated elevator handling. Applied Engineering in Agriculture, 2008; 24(5): 637-643.

[8] Llorens S, Pérez-Arjona I, Soliveres E, Espinosa V. Detection and target strength measurements of uneaten feed pellets with a single beam echosounder. Aquacultural Engineering, 2017; 78(B): 216-220.

[9] Haubjerg A F, Veje C, Jørgensen B N, Simonsen B, Løvgreen S. Structural properties and mechanical durability of extruded fish feed. Journal of Food Process Engineering, 2015; 38(6): 621-631.

[10] Aarseth K A, Prestløkken E. Mechanical Properties of feed pellets: Weibull analysis. Biosystems Engineering, 2003; 84(3): 349-361.

[11] Muramatsu K, Vaccari I C M, Minafra C S, Sens R F, Dahike F, Maiorka A. Effect of thermal processing, press throughput and roller-die gap on physicochemical properties of broiler feed pellets. Journal of Agricultural Science and Technology A, 2016; 6(2): 98-107.

[12] Tran Q D, Hendriks W H, van der Poel A F B. Effects of drying temperature and time of a canine diet extruded with a 4 or $8 \mathrm{~mm}$ die on physical and nutritional quality indicators. Animal Feed Science and Technology, 2011; 165(3-4): 258-264.

[13] Draganovic V, van der Goot A J, Boom R, Jonkers J. Assessment of the effects of fish meal, wheat gluten, soy protein concentrate and feed moisture on extruder system parameters and the technical quality of fish feed. Animal Feed Science and Technology, 2011; 165(3-4): 238-250.

[14] Bajwa D S, Peterson T, Sharma N, Shojaeiarani J, Bajwa S G. A review of densified solid biomass for energy production. Renewable and Sustainable Energy Reviews, 2018; 96: 296-305.

[15] Mani S, Tabil L, Sokhansanj S. Compaction of biomass grinds-an overview of compaction of biomass grinds. Powder Handling and Processing, 2003; 15(3): 160-168.

[16] Nevena M, Radmilo C, Duro V, Tea B, Salas B C. The effects of sugar beet molasses on wheat straw pelleting and pellet quality. A comparative study of pelleting by using a single pellet press and a pilot-scale pellet press. Fuel Processing Technology, 2016; 144: 220-229.

[17] Moritz J S, Cramer K R, Wilson K J, Beyer R S. Feed manufacture and feeding of rations with graded levels of added moisture formulated to different energy densities. Journal of Applied Poultry Research, 2003; 12(3): 371-381.

[18] Stein H H, Lagos L V, Casas G A. Nutritional value of feed ingredients of plant origin fed to pigs. Animal Feed Science and Technology, 2016; 218: 33-69.

[19] ASAE. Cubes, pellets, and crumbles-definitions and methods for determining density, durability, and moisture content. ASABE Standards, 2004.

[20] ASAE Standards S358. 2: Moisture measurement Forages. American Society of Agricultural Engineers, St. Joseph, MI, 2003.

[21] Thomas M, van der Poel A. Physical quality of pelleted animal feed 1. Criteria for pellet quality. Animal Feed Science and Technology, 1996; 61(1-4): 89-112.

[22] Moradi A, Moradi S, Abdollahi M R. Influence of feed ingredients with pellet-binding properties on physical pellet quality, growth performance, carcass characteristics and nutrient retention in broiler chickens. Animal Production Science, 2019; 59(1): 73-81.

[23] Muramatsu K, Massuquetto A, Dahlke F, Maiorka A. Factors that affect pellet quality: A review. Journal of Agricultural Science and Technology A, 2015; 5(9): 717-722.

[24] Singh S K, Muthukumarappan K. Effect of feed moisture, extrusion temperature and screw speed on properties of soy white flakes based aquafeed: a response surface analysis. Journal of the Science of Food and Agriculture, 2016; 96(6): 2220-2229.

[25] Tumuluru J S, Conner C C. Specific energy consumption and quality of wood pellets produced using high-moisture lodgepole pine grind in a flat die pellet mill. Chemical Engineering Research and Design, 2016; 110: 82-97.

[26] Tumuluru J S. Effect of process variables on the density and durability of the pellets made from high moisture corn stover. Biosystems Engineering, 2014; 119(4): 44-57.

[27] Jackson J, Turner A, Mark T, Montross M. Densification of biomas using a pilot scale flat ring roller pellet mill. Fuel Processing Technology, 2016; 148: 43-49. 